\title{
A wound assessment and management acronym: BE ME SIC SOS
}

\author{
W G Kleintjes, MMed (Plast), FC (Plast Surg) SA, PhD \\ Western Cape Provincial Tertiary Adult Burn Unit, Division of Surgery, Tygerberg Hospital and Stellenbosch University, South Africa
}

Corresponding author:W G Kleintjes (waynekleintjes@yahoo.com)

\author{
A wound assessment acronym, BE ME SIC SOS, was developed to aid consistent record keeping of wound healing and assist in teaching dressing \\ selections: $\mathrm{B}=$ biofilm; $\mathrm{E}=$ exudate/(o)edema; $\mathrm{m}=$ moistness; $\mathrm{E}=$ epithelialisation; $\mathrm{S}=$ slough; $\mathrm{I}=$ infection; $\mathrm{c}=\operatorname{colour} ; \mathrm{S}=$ size; \\ $\mathrm{O}=$ odour $; \mathrm{S}=$ swab need. \\ S Afr J Plast Reconstr Aesthet Surg Burns 2018;1(1):6-8. DOI: 10.7196/SAJPRASB.2018.v1i1.3
}

Wound assessment comprises the assessment of many factors. The TIME acronym ( $\mathrm{T}=$ tissue; $\mathrm{I}$ = infection/inflammation; $\mathrm{M}$ = moisture; $\mathrm{E}=$ epithelial edge) has been widely promoted and used for wound assessment. ${ }^{[1]}$ For the purpose of consistent wound assessment for our wound study purposes, there arose a demand for more information to be consistently extracted than that incorporated in TIME. The value of the new acronym is that it provides for consistent wound descriptions in record keeping and of the clinical presentation of wounds, and consistent parameters for research purposes. It is also a useful method for teaching wound assessment to medical students and other personnel.

\section{Methods}

Several wound assessment parameters can be used, for example infection, slough, odour, colour, epithelialisation, size, biofilm, moistness, dryness, exudate and others. For the purposes of information needed for wounddressing studies, we identified 10 factors that would be valuable. The first letters of these 10 factors were then arranged to form an acronym that could be easily memorised.

\section{Results}

The final acronym selected was BE ME SIC SOS. The reasoning behind the choice was that it was logical that if you (ME) are (BE) very sick (SIC) you would need help (SOS ='save our souls').

$$
\begin{aligned}
& B=\text { biofilm } \\
& E=\text { exudate; (o)edema } \\
& M=\text { moistness } \\
& \mathrm{E}=\text { epithelialisation } \\
& \mathrm{S}=\text { slough } \\
& \mathrm{I}=\text { infection } \\
& \mathrm{C}=\text { colour } \\
& \mathrm{S}=\text { size } \\
& \mathrm{O}=\text { odour } \\
& \mathrm{S}=\text { swab need. }
\end{aligned}
$$

\section{Discussion}

Wound assessment acronyms are useful in selecting an appropriate dressing, and the BE ME SIC SOS acronym can assist the user in this. ${ }^{\left[{ }^{[]}\right.}$
The role and importance of biofilms has been highlighted in many articles. ${ }^{[1,3]}$ Although the diagnosis of biofilm seems simple by pathological examination made under a microscope, the clinical diagnosis of biofilm on a wound based on visual inspection remains controversial. ${ }^{[4]}$ Just like slime on a rock in a river represents biofilm, the biofilm wound looks shiny and slimy, and a gloved finger slides easily over it.

Exudate volumes are important to manage..$^{[5]}$ They can range from none to high volumes, and this affects the choice of dressing, as well as duration of dressing. Oedema in a wound affects wound healing; many things can be done to address the problem, such as simple limb elevation and pressure dressings.

Moist wound healing has been shown to be hugely beneficial. ${ }^{[6]}$ Excessive moistness is not good for certain wounds, however, for example, those infected with Pseudomonas aeruginosa. Finding the right balance and selecting the correct dressing based on this dynamic factor is very important for optimal healing. ${ }^{[1,2]}$

Epithelialisation of a wound is a sign of the skin healing. Several dressings can enhance epithelialisation, such as honey and dialkylcarbomyochlorideimpregnated dressings, while some silver dressings can delay it. ${ }^{[7.8]}$

Slough on a wound will delay healing and promote infection, and therefore it is an important factor to consider.

Infection is always important to recognise or suspect on a wound. Pus and redness (inflammation/cellulitis) of the wound are typical of infection.

The colour of a wound can reveal a lot of information, and therefore has to be included in the checklist. Red wounds can be an indication of good blood supply, compared with blueish yellow or black areas that would indicate poor blood flow in those areas. Redness around the wound could indicate inflammation and/or cellulitis. White or pale wounds could indicate poor arterial inflow, whereas purple or blueish wounds may indicate venous problems. Black spots could be signs of necrosis, or result from fungal infections.

The size of a wound can indicate the progress of the wound. If it gets smaller, then it is a positive sign, conversely, if it gets bigger, it is a negative one.

Odour is one indication of how well or badly the wound is healing, or whether there is infection or not. ${ }^{[9]}$ Usually a bad odour would 


\section{ARTICLE}

correspond to a local wound infection. Certain bacteria on wounds cause characteristic odours.

If one feels the need to swab the wound, this could be an indication of how worried one may feel about infection, in a wound where infection is not overtly evident. ${ }^{[10]}$ Sometimes a wound does not look infected, but there may be a clinical concern that there is occult infection. In this case, one would do a wound swab. When looking at records retrospectively, this information can be useful to help understand the condition of the wound and the concerns of the treating doctor.

\section{Conclusion}

The BE ME SIC SOS acronym is useful for teaching wound assessment, and has the benefit of providing consistent record keeping of wound progression for clinical wound monitoring, and for wound studies. The information can also be used to tailor appropriate wound dressings. In our burn unit, it has replaced the TIME acronym. In a way, it can be said that the 'TIME' to move on with the wound assessment and management acronym has arrived, in BE ME SIC SOS.
Acknowledgements. None.

Author Contributions. Sole author.

Funding. None.

\section{Conflicts of interest. None.}

1. Leaper DJ, Schultz G, Carville $K$, et al. Extending the TIME concept: What we have learned in the past 10 years? Int Wound J 2014;9(Suppl 2):1-19. https://doi.org/10.1111/j.1742-481X.2012.01097.x

. Carville K. Which dressing should l use? It all depends on 'TIMEING'. Aust Fam Physician 2006;35(7):486-489. 3. Swanson T, Wolcott RD, Wallis H. Understanding biofilm in practice: A global survey of health professionals. J Wound Care 2017;26(8):426-440. https://doi.org/10.12968/jowc.2017.26.8.426

4. Bianchi T, Wolcott RD, Peghetti A, et al. Recommendations for the management of biofilms: A consensus document. J Wound Care 2016;25(6):305-317. https://doi.org/10.12968/jowc.2016.25.6.305.

5. Davies P. Exudate assessment and management. Br J Community Nurs 2012;Suppl:S18-22.

6. Alper JC, Welch EA, Ginsberg M, et al. Moist wound healing under a vapor permeable membrane. J Am Acad Dermat 1983;8(3):347-353.

7. Kleintjes WG, Schoeman D, Collier L. A pilot study of Cuitmed Sorbact v. Acticoat v. Silverlon for the treatment of burn wounds in a South African adult burns unit. Wound Healing J South Afr 2015;8(2):22-29.

8. Kleintjes WG, du Toit DF. Ex-vivo study comparison of Mebo, Melladerm, and platelet-rich plasma. Specialist Forum 2012;12(6):14-15.

9. Gethin G, Grocott P. Probst S, et al. Current practice in the management of wound odour. Int I Nurs Stud 2014:51(6):865-874. https://doi.org/10.1016/.i.jnurstu.2013.10.013

10. Halstead FD, Lee KC, Kwei J, et al. A systematic review of quantitative burn wound microbiology in the management of burns patients. Burns 2018:44(1):39-56. https://doi.org/10.1016/j.burns.2017.06.008

Accepted 8 November 2018 